\title{
Endovascular stent grafting for ascending aorta repair in high-risk patients
}

\author{
Eric E. Roselli, MD, Jahanzaib Idrees, MD, Roy K. Greenberg, MD, Douglas R. Johnston, MD, and \\ Bruce W. Lytle, MD
}

\begin{abstract}
Objectives: Standard treatment of ascending aortic pathology is open repair, but some patients are too high risk. Thoracic endovascular aortic repair (TEVAR) of the ascending aorta has been used as an alternative. Our objectives were to characterize patients, describe repair methods, and assess outcomes.
\end{abstract}

\begin{abstract}
Methods: From 2006 to 2014, 22 patients underwent supracoronary ascending TEVAR for acute Type A dissection $(n=9)$, intramural hematoma $(n=2)$, pseudoaneurysm $(n=9)$, chronic dissection $(n=2)$, or aorta-cardiac fistula $(\mathrm{n}=2)$. Mean age was $71 \pm 13$ years and the maximum proximal aortic diameter was $6 \pm 1 \mathrm{~cm}$. Devices were delivered via a transfemoral $(\mathrm{n}=10)$, transapical $(\mathrm{n}=7)$, or axillary $(\mathrm{n}=5)$ artery approach. The proximal landing zone was at the sinotubular junction in 14 patients, mid to distal ascending aorta in 3 patients, and surgical graft from previous ascending repair in 5 patients. More than 1 device was used in 15 patients. Imaging and engineering analysis was performed for all patients.
\end{abstract}

Results: There were 3 hospital deaths (13.6\%) (tamponade in 1 patient, bleed from left atrial fistula in another patient). One patient had partial occlusion of the left coronary artery requiring open conversion and died later from multiorgan failure. One patient required early open conversion for retained delivery system. There were 3 strokes, 2 myocardial infarctions, and 2 tracheostomies, but there was no new-onset renal failure. Median follow-up was 12 months. Six patients developed type 1 endoleak: 2 were treated endovascularly, 1 with open repair, 1 resolved, 1 refused treatment, and 1 is being watched. In 2 patients, initial TEVAR was performed as a bridge for ruptured high-risk dissection and were later converted to open repair. Reoperations also included removal of stent graft due to distal migration and repair of left ventricular pseudoaneurysm. There were 3 late deaths. Actual survival at 30 days, 1 year, and 5 years was $86 \%, 80 \%$, and $75 \%$, respectively.

Conclusions: Ascending TEVAR is a feasible alternative to medical therapy for repair of acute and chronic ascending disease in high-risk patients. Development of devices dedicated to treat ascending aortic pathology is needed to improve outcomes. (J Thorac Cardiovasc Surg 2015;149:144-54)

Video clip is available online.

Conventional treatment of ascending aortic aneurysm or dissection is open repair, but some patients are too high risk for this approach and may benefit from a less invasive alternative with thoracic endovascular aortic repair (TEVAR). ${ }^{1-4}$

Several studies have reported safety and effectiveness of TEVAR of the descending aorta, but the role of TEVAR for

From the Department of Thoracic and Cardiovascular Surgery, Heart and Vascular Institute, Cleveland Clinic, Cleveland, Ohio.

Disclosures: Eric E. Roselli reports consulting fees from Cook and Medtronic, and lecture fees from Vascutek. The other authors have nothing to disclose with regard to commercial support.

Read at the 40th Annual Meeting of The Western Thoracic Surgical Association, Dana Point, California, June 25-28, 2014.

Received for publication June 25, 2014; accepted for publication July 13, 2014; available ahead of print Oct 11, 2014.

Address for reprints: Eric E. Roselli, MD, Department of Thoracic and Cardiovascular Surgery, Heart and Vascular Institute, Cleveland Clinic, 9500 Euclid Ave, Desk J4-1, Cleveland, OH 44195-5108 (E-mail: roselle@ccf.org).

$0022-5223 / \$ 36.00$

Copyright (c) 2015 by The American Association for Thoracic Surgery

http://dx.doi.org/10.1016/j.jtcvs.2014.07.109 treating ascending aortic pathology is less well known. Only a small number of studies have described outcomes with this approach. ${ }^{4-11}$

Currently there are no commercially available endovascular devices specifically designed to treat the ascending aorta. Compared with TEVAR of the descending thoracic aorta, endovascular therapy for the ascending aorta is challenged by more complex pathology, hemodynamic characteristics, and anatomy. Despite these issues, we have used various endovascular devices to treat high-risk patients without other reasonable treatment options.

Objectives of our study were to explore the feasibility of TEVAR as an alternative to medical therapy for treating ascending aorta pathology in high-risk patients. Patients are characterized, outcomes are assessed, and recommendations for improvement are formulated based on imaging and engineering analysis.

\section{PATIENTS AND METHODS}

\section{Patient Characteristics and Risk Factors}

From 2006 to 2014, 22 patients underwent endovascular supracoronary ascending aortic repair at Cleveland Clinic. Presentation and indications for repair included acute Type A dissection $(n=9 ; 41 \%)$, acute intramural 


\section{Abbreviations and Acronyms \\ $\mathrm{CT}=$ computed tomography \\ TEVAR $=$ thoracic endovascular aortic repair}

hematoma ( $\mathrm{n}=2 ; 9 \%)$, pseudoaneurysm $(\mathrm{n}=9 ; 36 \%)$, and chronic dissection with aneurysm $(n=2 ; 9 \%)$. One patient presented with hemoptysis and heart failure due to a pseudoaneurysm to pulmonary artery fistula, and another presented with heart failure due to acute dissection of a chronic aneurysm that developed fistula into the dome of the left atrium. Mean age was $70 \pm 13$ years, $50 \%$ were men, and the preoperative mean maximum aortic diameter was $6 \pm 1.0 \mathrm{~cm}$.

Sixteen patients $(73 \%)$ had a history of previous major cardiac or aortic operation and of these, 4 had multiple previous cardiac operations. All patients were considered too high risk for conventional open repair at the time of presentation. Additional patient details are summarized in Table 1. Imaging analysis. Detailed imaging analysis was performed in all patients. Computed tomography (CT) scans were reviewed using 3-dimensional imaging software (Terarecon, San Mateo, Calif). Aortic and branch vessel diameter measurements were obtained at multiple landmarks. Length measurements were also taken from the highest coronary to the origin of brachiocephalic artery along 3 paths: the greater curvature, central line of flow, and the lesser curvature. These results are summarized in Table 2.

\section{Presentation}

Acute Type A dissection and intramural hematoma. All acute Type A dissection patients $(\mathrm{n}=9 ; 41 \%)$ presented as an emergency. Of these, 4 patients $(44 \%)$ had pericardial effusion, including 1 patient who refused blood transfusion for religious reasons. Four patients $(44 \%)$ presented with moderately severe aortic insufficiency, whereas 3 patients $(33 \%)$ had respiratory failure - 1 already had tracheostomy in place at the time of presentation and the other 2 were intubated on arrival. Two additional patients presented with chest pain and intramural hematoma with a penetrating ulcer and were treated urgently (Figure 1). All patients in this group were deemed extremely high risk for open repair but had the potential for a reasonable quality of life if they were to survive the acute insult. Endovascular therapy was chosen over medical therapy for 1 of 2 reasons: they had favorable morphology believed to be amenable to definitive repair or they had unfavorable morphology that put them at immediate risk of death without mechanical treatment. The latter were treated with the understanding that the endovascular approach may serve as a bridge to later definitive open repair if their risk improved.

Ascending pseudoaneurysm. In contrast to patients with acute Type A dissection, 8 patients with ascending pseudoaneurysm presented in a stable condition, except for 1 who presented with hemoptysis, respiratory failure, and cardiogenic shock due to an $8.6-\mathrm{cm}$ pseudoaneurysm with a fistula to the right main pulmonary artery in the setting of chronic dissection beyond a previous repair. All patients had a history of previous cardiac surgery and the mean interval to ascending TEVAR was $6.4 \pm 5$ years. Previous procedures included coronary bypass in 4 patients who developed pseudoaneurysm at the site of a proximal vein graft anastomosis. In the other 5 patients, the prior procedure included root and ascending aortic repair for dissection or aneurysm and aortic valve replacement $(n=4)$ or resuspension $(n=1)$. In these patients the pseudoaneurysm arose near the site of the distal graft anastomosis to native aorta (Figure 2).

Chronic dissection. Two patients presented with complications related to residual chronic dissection after acute Type A repair. Both patients had a small communication between the true and false lumen at the distal anastomosis of the ascending graft. One patient had persistent hemolysis without another source for anemia and required $>30$ units of blood transfused over a 4-month period with severe left ventricular dysfunction (ejection fraction, $10 \%-15 \%$ ) without clear etiology. The other patient had growth of her arch by approximately $15 \mathrm{~mm}$ only 4 months following the initial emergency dissection repair (Figure 3). Ascending TEVAR was technically successful in the second patient, but the other required emergency conversion for a retained delivery system. The delivery system was removed under circulatory arrest and the stent graft was left intact.

\section{Operative Details and Technique}

Stent grafts were used in 21 patients (95\%) (see Table 3). In 1 patient attempted stent graft delivery was aborted due to difficulty in crossing an existing mechanical aortic valve. This is the patient who presented with pseudoaneurysm after previous Type A repair and fistula from the aorta to pulmonary artery. The pulmonary artery and aortic defects were plugged with atrial septal closure devices and the aorta device was reinforced by a balloon-expandable stent in the ascending aorta.

All procedures were done under general anesthesia with heparin for anticoagulation. Device delivery was transfemoral $(\mathrm{n}=10)$, transapical $(n=7)$, or through the axillary artery $(n=5)$. Transfemoral delivery was performed through a cut-down exposure of the common femoral artery and stiff wire access across the aortic valve. For transapical delivery, through and through wire access into the left subclavian artery was obtained using a snare technique. Axillary artery approach was performed through a 10-mm surgical graft conduit. In 1 patient with very severe left ventricular dysfunction due to untreated hypothyroidism, the device was deployed while the patient was on full cardiopulmonary bypass. In all others, hemodynamic displacement forces were reduced by rapid ventricular pacing during the device deployment. Transesophageal echocardiography was used in addition to fluoroscopic guidance. Completion angiogram was performed to assess coronary and brachiocephalic vessel patency, and to rule out endoleak. All patients were transferred to the intensive care unit intubated.

In patients who underwent ascending aortic stent grafting, 16 out of 21 patients had proximal landing zone in the native proximal aorta: sinotubular junction in 13 and mid to distal ascending aorta in 2 patients. In the other 5 patients, the proximal landing zone was a surgical graft from previous open ascending aortic repair. More than 1 device was used in 14 patients $(64 \%)$.

Additional intraoperative procedures. Five patients had coronary artery access obtained during the ascending repair. In 2 patients, coronary intervention was planned: a clinically important circumflex artery stenosis was stented and a saphenous vein graft where pseudoaneurysm originated was coiled to avoid type 2 endoleak. In 3 others, wire access was obtained due to concern that the device would be deployed close to the origin.

Two patients required intraoperative open conversion to manage acute complications. In 1 patient who underwent transfemoral emergency TEVAR for acute Type A dissection, there was a partial occlusion of the left coronary artery by the stent graft. The patient was immediately placed on cardiopulmonary bypass support via cannulation of the femoral vessels. Initial attempts at balloonfacilitated repositioning was not successful. During hypothermic circulatory arrest, the stent graft was removed and the ascending aorta was replaced. This patient died on postoperative day 6 due to stroke and multiorgan failure. A second patient who required open conversion had chronic dissection after previous Type A repair. This patient had persistent hemolysis from a small entry tear at the distal suture line. The device was delivered from the left axillary artery. After deploying the stent graft, a portion of the delivery system was retained. Following multiple failed attempts at removal of the delivery system, the patient was placed on cardiopulmonary bypass support, cooled, and redo sternotomy was performed. Previous surgical graft was opened and the delivery system released. The remaining proximal end of the stent graft was secured with sutures and the aortotomy was closed. 
TABLE 1. Patient characteristics

\begin{tabular}{|c|c|c|c|c|}
\hline & $\begin{array}{c}\text { Overall } \\
(N=22)\end{array}$ & $\begin{array}{c}\text { Acute Type } \\
\text { A/IMH }(\mathbf{n}=\mathbf{1 1})\end{array}$ & $\begin{array}{c}\text { Ascending } \\
\text { pseudoaneurysm }(n=9)\end{array}$ & $\begin{array}{c}\text { Chronic dissection } \\
(\mathbf{n}=2)\end{array}$ \\
\hline Mean age, y & $72 \pm 10$ & $75 \pm 10$ & $69 \pm 8$ & $70 \pm 3$ \\
\hline Male & $11(50)$ & $5(50)$ & $7(78)$ & $1(33)$ \\
\hline \multicolumn{5}{|l|}{ Baseline comorbidities } \\
\hline Hypertension & $20(91)$ & $11(100)$ & $9(100)$ & $2(100)$ \\
\hline Coronary artery disease & $11(50)$ & $4(36)$ & $7(78)$ & $0(0)$ \\
\hline Prior myocardial infarction & $6(27)$ & $4(36)$ & $2(22)$ & $0(0)$ \\
\hline Prior stroke & $4(18)$ & $3(27)$ & $1(11)$ & $0(0)$ \\
\hline Chronic obstructive pulmonary disease & $6(27)$ & $4(36)$ & $3(33)$ & $0(0)$ \\
\hline Chronic renal insufficiency & $5(23)$ & $2(18)$ & $3(33)$ & $0(0)$ \\
\hline Atrial fibrillation & $5(23)$ & $3(27)$ & $1(11)$ & $1(50)$ \\
\hline Congestive heart failure & $8(36)$ & $2(18)$ & $5(63)$ & $1(50)$ \\
\hline Coagulopathy & $3(14)$ & $3(27)$ & $1(11)$ & $0(0)$ \\
\hline Respiratory failure & $2(9)$ & $2(18)$ & $1(11)$ & $0(0)$ \\
\hline Pericardial effusion & $4(18)$ & $4(36)$ & $0(0)$ & $0(0)$ \\
\hline$\geq$ Moderately severe aortic insufficiency & $4(18)$ & $4(36)$ & $0(0)$ & $0(0)$ \\
\hline Mild to moderate mitral regurgitation & $11(50)$ & $4(36)$ & $5(63)$ & $2(100)$ \\
\hline Malignancy & $5(23)$ & $2(18)$ & $1(13)$ & $2(100)$ \\
\hline Diabetes & $3(14)$ & $3(27)$ & $0(0)$ & $0(0)$ \\
\hline Liver failure & $1(5)$ & $0(0)$ & $1(13)$ & $0(0)$ \\
\hline Prior cardiac/aortic surgery & $16(73)$ & $5(45)$ & $9(100)$ & $2(100)$ \\
\hline
\end{tabular}

Values are presented as mean \pm standard deviation or $\mathrm{n}(\%)$. Type A, Type A dissection; $I M H$, intramural hematoma.

One patient was placed on cardiopulmonary bypass temporarily after stent-grafting an acute dissection due to poorly tolerated rapid ventricular pacing, but was easily weaned after resuscitation. Two other patients had temporary coverage of a coronary artery by the stent graft, but were salvaged by balloon repositioning of the device distally (Coda; Cook, Bloomington, Ind) (Figure 1). Both had immediate hemodynamic recovery, normalization of the electrocardiogram, and no clinical sequelae of the ischemic event.

\section{Definitions, Follow-up, Statistics, and Engineering Analysis}

Stroke was defined as neurologic deficit lasting $>24$ hours confirmed by cross-sectional imaging of the brain or documentation by a neurologist. Renal failure was defined as the need for hemodialysis and respiratory failure was defined as the need for reintubation or tracheostomy postoperatively. CT was performed before discharge and during outpatient

TABLE 2. Imaging analysis

\begin{tabular}{|c|c|c|c|c|}
\hline & $\begin{array}{l}\text { Overall } \\
(N=22)\end{array}$ & $\begin{array}{l}\text { Acute type A/ } \\
\text { IMH }(\mathbf{n}=11)\end{array}$ & $\begin{array}{c}\text { Ascending } \\
\text { pseudoaneurysm }(n=9)\end{array}$ & $\begin{array}{c}\text { Chronic dissection } \\
(\mathbf{n}=\mathbf{2})\end{array}$ \\
\hline \multicolumn{5}{|l|}{ Aortic diameter, $\mathrm{cm}$} \\
\hline Mean maximum ascending & $5.9 \pm 2$ & $5.86 \pm 1$ & $6.2 \pm 0.8$ & $4.7 \pm 0.6$ \\
\hline Maximum diameter at sinotubular junction & $3.8 \pm 1$ & $4.5 \pm 1$ & $3.6 \pm 0.3$ & $3.9 \pm 0.2$ \\
\hline TL or inner diameter at sinotubular junction & $3.4 \pm 1$ & $3.6 \pm 0.5$ & $3.1 \pm 0.3$ & $3.6 \pm 0.05$ \\
\hline Maximum distal ascending diameter & $4.6 \pm 1$ & $4.1 \pm 0.6$ & $5 \pm 1$ & $4.7 \pm 0.5$ \\
\hline TL or inner distal ascending diameter & $3.4 \pm 2$ & $3.4 \pm 0.5$ & $3.4 \pm 0.4$ & $3.9 \pm 0.2$ \\
\hline \multicolumn{5}{|l|}{ Length highest coronary to innominate artery } \\
\hline Greater curvature & $9.6 \pm 2$ & $10 \pm 2$ & $9.3 \pm 1$ & $9.7 \pm 0.1$ \\
\hline Central & $7.8 \pm 1$ & $7.8 \pm 1$ & $7.9 \pm 1$ & $7.8 \pm 005$ \\
\hline Lesser curvature & $6.4 \pm 1$ & $6.3 \pm 1$ & $6.3 \pm 0.9$ & $6.3 \pm 0.9$ \\
\hline Distance: Entry tear/pseudoaneurysm to coronary artery & $3.1 \pm 1$ & $1.8 \pm 0.3$ & $3.8 \pm 1$ & $5.1 \pm 1$ \\
\hline Distance: Entry tear/pseudoaneurysm to innominate artery & $3.6 \pm 2$ & $4.1 \pm 2$ & $3.5 \pm 1$ & $2.3 \pm 0.3$ \\
\hline Size of defect (entry tear/pseudoaneurysm neck) & $17 \pm 8$ & $1.5 \pm 0.4$ & $2.1 \pm 0.8$ & - \\
\hline \multicolumn{5}{|l|}{ Aortic arch anatomy } \\
\hline \multicolumn{5}{|l|}{ Mean diameter, $\mathrm{cm}$} \\
\hline Left subclavian artery & $1.2 \pm 0.1$ & $1.2 \pm 0.2$ & $1.2 \pm 0.4$ & $1.2 \pm 0.1$ \\
\hline Left common carotid & $1.5 \pm 0.6$ & $1.4 \pm 0.5$ & $1.4 \pm 0.6$ & $1.4 \pm 0.6$ \\
\hline Innominate artery & $1.9 \pm 0.5$ & $1.7 \pm 0.4$ & $1.8 \pm 0.5$ & $1.9 \pm 0.5$ \\
\hline Bovine arch & 4 & 2 & 1 & 1 \\
\hline Branch head vessel involvement & 3 & 3 & 0 & 0 \\
\hline
\end{tabular}

Values are presented as mean \pm standard deviation or number. Type A, Type A dissection; $I M H$, intramural hematoma; $T L$, true lumen. 


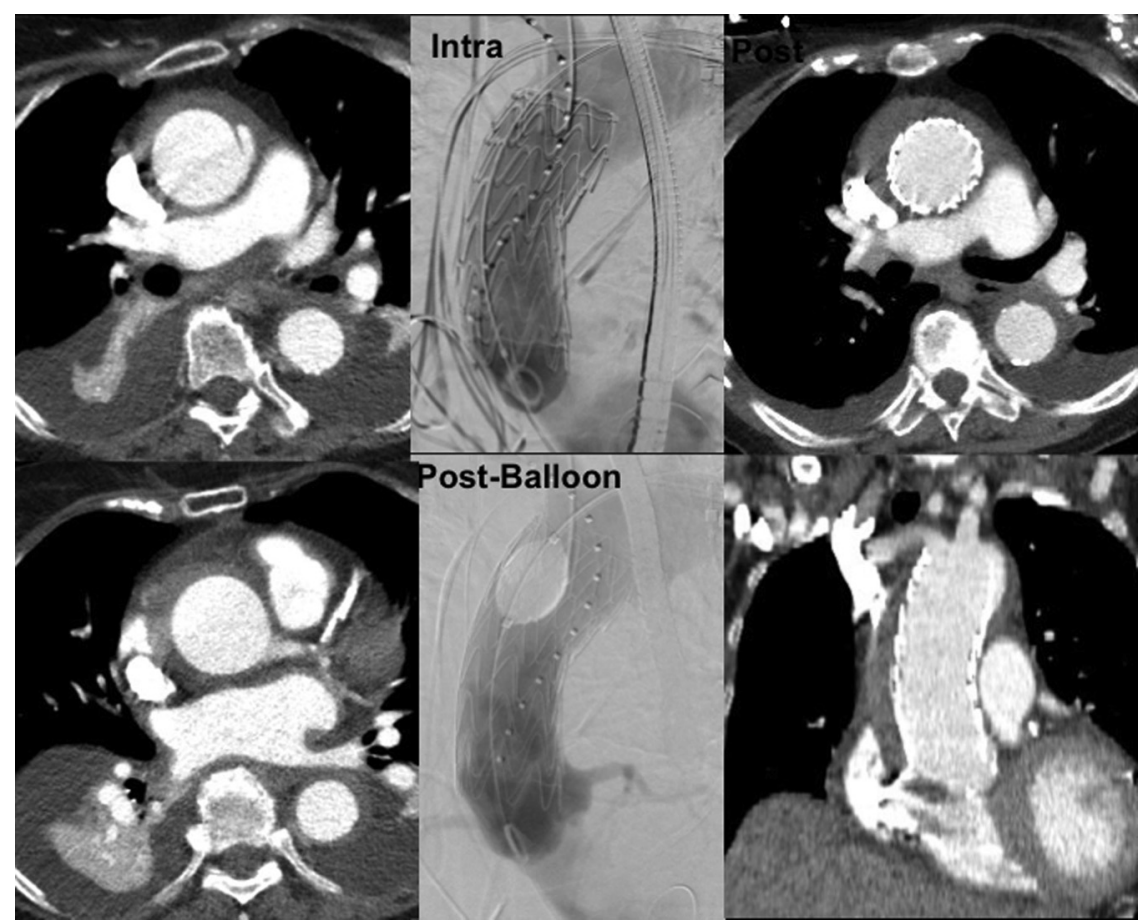

FIGURE 1. Preoperative computed tomography, intraoperative fluoroscopy (intra), and postoperative images (post-balloon) of a patient with an ascending intramural hematoma complicated by temporary coronary artery coverage rescued by balloon repositioning.

follow-up scheduled at 3 months then annually unless otherwise indicated. Median follow-up was 12 months.

Descriptive statistical analyses are used to present variables for the study. Continuous variables are presented as median or mean \pm standard deviation, and categorical variables are presented as percentages.

Each operation was retrospectively reviewed from the initial planning stages through late follow-up imaging with a critical eye toward improvement. An ideal result was that in which the device primarily and definitively treated the presenting indicated problem in a manner comparable to the desired expected result of stent grafting for an on-label indication without life-threatening intraoperative or hospital complications. All others were considered to have fallen short of this ideal. Shortcomings of each operation were classified as being related to the patient, device, or delivery issues. Patients' issues included anatomic,
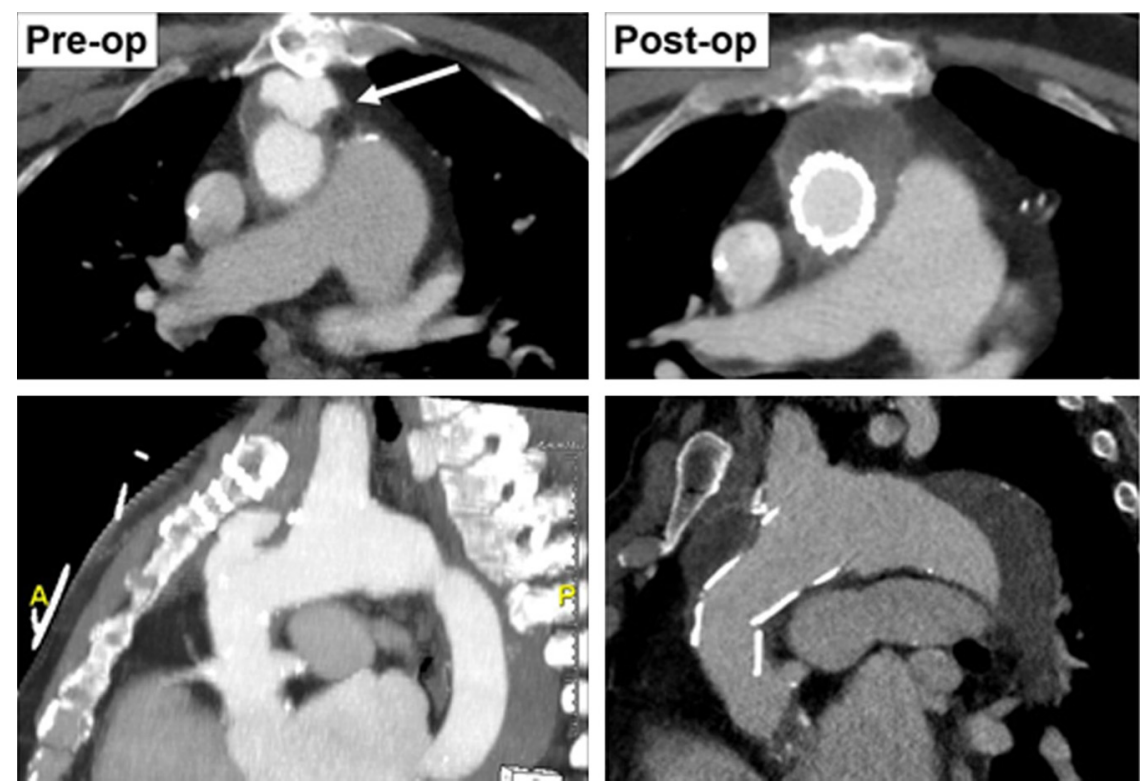

FIGURE 2. Pre- (pre-op) and postoperative (post-op) reconstructed computed tomography images of a patient with an ascending pseudoaneurysm after previous root replacement. 


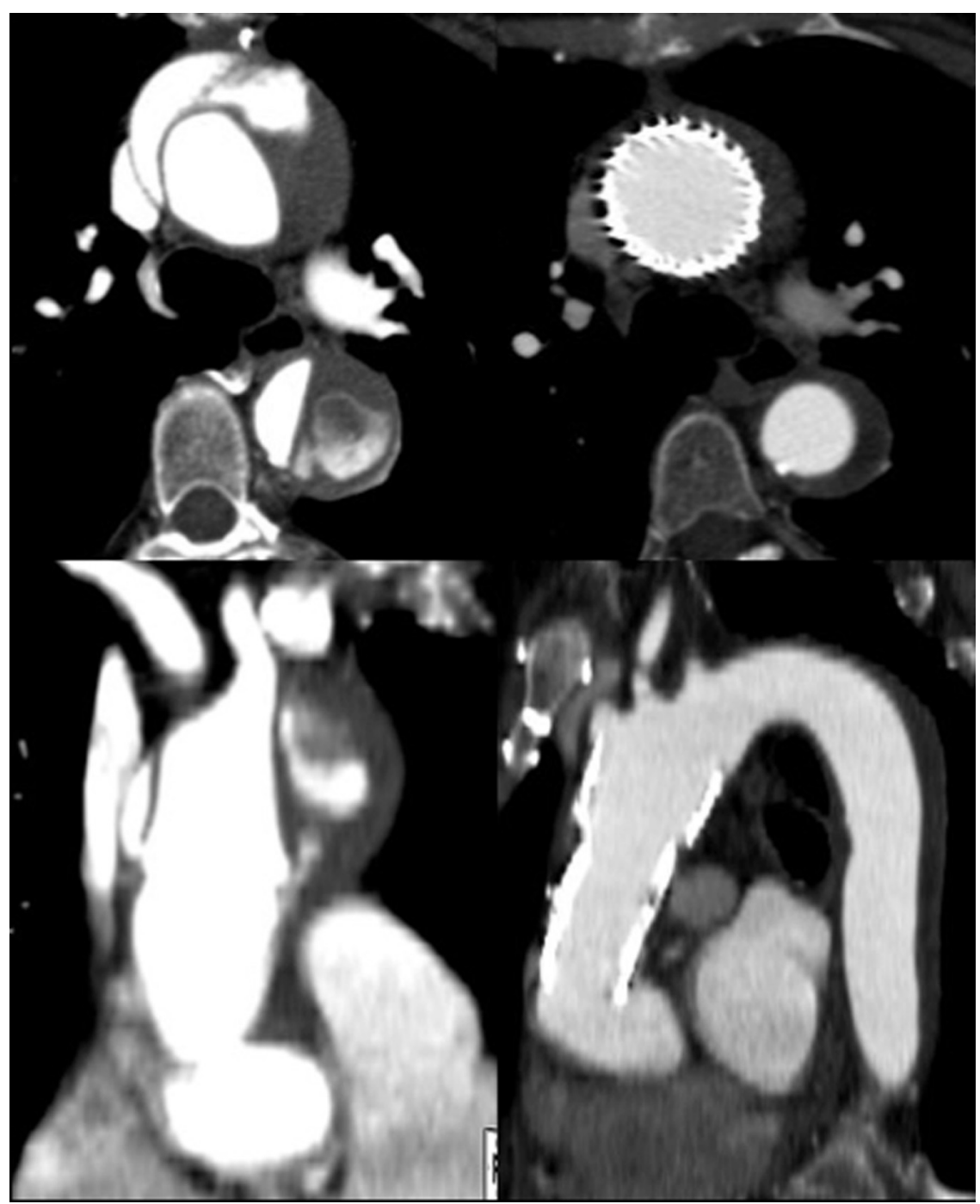

FIGURE 3. Pre- and postoperative (3 months) reconstructed computed tomography images of a patient with chronic dissection and rapid aneurysm growth.

morphologic, or physiologic concerns. Device-related issues included factors like size, shape, fixation, and conformability. Delivery modes of failure included access, mode of expansion, and accuracy in positioning.

\section{RESULTS}

\section{Early}

Two patients $(9 \%)$ required early conversion to open repair as described above. There were 3 hospital deaths $(13.6 \%) ; 1$ was intraoperative. All 3 underwent emergency repair of acute Type A dissection. One refused blood transfusions for religious reasons and died on postoperative day 4 due to rupture and tamponade. Another had a dissected chronic ascending aneurysm that eroded into the left atrium and bled from the left atrium after ascending stent grafting and resulted in tamponade and intraoperative death. The third patient died from multiorgan failure on postoperative day 6 after partial occlusion of the left coronary artery required conversion to open repair. The patient who required open conversion for a retained delivery system tolerated the repair, stopped hemolyzing, and had full recovery of his systolic function but required later reoperation for an apical pseudoaneurysm. This patient is still alive and doing well 4 years later.

Three patients $(13.6 \%)$ had stroke, 2 had myocardial infarction ( $9 \%$ ), and 2 patients ( $9 \%$ ) required tracheostomy for respiratory failure. Six patients had a history of chronic renal insufficiency, but there was no new onset renal failure requiring dialysis.

\section{Late}

There were 3 late deaths: 1 patient died of lung cancer, 1 died of pneumonia, and the cause is unknown in the third. The latter was a 91-year old man who experienced a stroke and was discharged to a nursing facility where he died. Actual survival at 30 days, 1 year, and 5 years was $86 \%$, 
TABLE 3. Operative details

\begin{tabular}{|c|c|c|c|c|c|c|c|}
\hline Patient & Age & Gender & Indication & Appr. & Device(s) & Outcome & Details/events \\
\hline 1 & 91 & M & Type A & TA & Gore, Medtronic & Late death & COD: unknown \\
\hline 2 & 56 & $\mathrm{~F}$ & Type A & $\mathrm{TA}$ & Cook & $\begin{array}{l}\text { Endo Reintv } \\
\text { Late death }\end{array}$ & $\begin{array}{l}\text { Type } 1 \text { endoleak } \rightarrow \text { TEVAR extension with talent } \\
\text { COD: pneumonia }\end{array}$ \\
\hline 3 & 79 & M & Type A & $\mathrm{TF}$ & Cook & Late death & COD: Lung cancer \\
\hline 4 & 75 & $\mathrm{~F}$ & Type A & $\mathrm{TF}$ & Gore & Acute death & Endoleak, rupture \\
\hline 5 & 82 & $\mathrm{~F}$ & Type A & $\mathrm{TF}$ & Cook & Acute death & LM coverage $\rightarrow$ open conversion, COD: multi-organ failure \\
\hline 6 & 51 & $\mathrm{~F}$ & Type A & TA & Cook & Alive & Early endoleak resolved, definitive repair \\
\hline 7 & 84 & M & Type A & TA & Cook & Acute death & COD: bleeding aorto-atrial fistula, tamponade \\
\hline 8 & 83 & $\mathrm{~F}$ & Type A & $\mathrm{TA}$ & Cook & Alive & Type 1 endoleak, refused reintervention \\
\hline 9 & 79 & M & Type A & $\mathrm{TF}$ & Gore & Endo, open reintv & $\begin{array}{l}\text { TEVAR treated rupture } \rightarrow \text { type } 1 \text { endoleak } \rightarrow \text { endo extension, } \\
\text { later open repair }\end{array}$ \\
\hline 10 & 69 & $\mathrm{~F}$ & IMH & TA & Cook & Alive & Definitive repair \\
\hline 11 & 81 & $\mathrm{~F}$ & $\mathrm{IMH}$ & $\mathrm{TF}$ & Gore & Alive & Definitive repair \\
\hline 12 & 38 & M & PseudoA & TAx & $\mathrm{ASD}+\mathrm{BMS}$ & Open Reintv & $\begin{array}{l}\text { PseudoA—Pulmonary artery fistula plugged as bridge to open } \\
\text { repair } \rightarrow \text { open ascending arch repair } \\
\text { Definitive repair }\end{array}$ \\
\hline 13 & 84 & M & PseudoA & $\mathrm{TF}$ & Medtronic & Alive & Definitive repair \\
\hline 14 & 63 & $\mathrm{~F}$ & PseudoA & $\mathrm{TF}$ & Cook & Alive & Definitive repair \\
\hline 15 & 55 & M & PseudoA & TAx & Cook & Open Reintv & $\begin{array}{l}\text { PseudoA resolved } \rightarrow \text { Stent migration to arch on } \mathrm{CT} \rightarrow \text { open } \\
\text { retrieval }\end{array}$ \\
\hline 16 & 73 & M & PseudoA & $\mathrm{TF}$ & Cook & Alive & Definitive repair \\
\hline 17 & 63 & M & PseudoA & TAx & Cook & Endo Reintv & $\begin{array}{l}\text { Definitive repair coil embolization into pseudoA at endoleak, } \\
\text { definitive repair }\end{array}$ \\
\hline 18 & 64 & M & PseudoA & TA & Cook & Alive & Definitive repair \\
\hline 19 & 88 & M & PseudoA & TAx & Gore & Alive & Definitive repair \\
\hline 20 & 61 & $\mathrm{~F}$ & PseudoA & $\mathrm{TF}$ & Cook & Alive & Small endoleak, monitored \\
\hline 21 & 64 & M & C.Dissection & TAx & Cook & Open Reintv & $\begin{array}{l}\text { 1. Retained delivery system } \rightarrow \text { open conversion direct device } \\
\text { fixation } \\
\text { 2. Late left ventricular apex pseudoaneurysm repair, definitive repair }\end{array}$ \\
\hline 22 & 74 & $\mathrm{~F}$ & C.Dissection & $\mathrm{TF}$ & Cook & Alive & Definitive repair \\
\hline
\end{tabular}

Appr., Approach for device delivery; $M$, male; Type A, acute type A dissection; TA, transapical; COD, cause of death; F, female; Endo, endovascular; Reintv, reintervention; $T E V A R$, thoracic endovascular aortic repair; $I M H$, intramural hematoma; $T F$, transfemoral; $L M$, left main coronary artery; $T A x$, transaxillary; $A S D$, atrial septal defect closure device; BMS, bare metal stent; PseudoA, pseudoaneurysm; CT, computed tomography; C.Dissection, chronic dissection.

$77 \%$, and $73 \%$, respectively. Six of 19 survivors $(32 \%)$ required late reinterventions ( 4 open, 2 endovascular).

\section{Late Reinterventions}

One patient had distal migration of the stent graft into his arch found incidentally during follow-up CT at 6 months. The patient had no symptoms, but his pseudoaneurysm had completely resolved. The pseudoaneurysm repair was done endovascularly because he was acutely ill, but he had since recovered and was taken electively for open extraction of the device. The other late unanticipated reoperation was performed for left ventricular apex pseudoaneurysm caused by wire perforation in the patient who had difficult delivery system extraction.

In 2 other patients, open reoperations were planned. At the time of initial emergency TEVAR both patients were too sick for open repair. One had acute dissection and rupture only 2 months following mitral repair and coronary bypass grafting complicated by myocardial infarction requiring coronary stenting. The rupture was successfully treated by stent grafting and the residual dissection and aneurysm were treated 4 months later when clopidogrel could be safely stopped. The other patient presented with hemoptysis, in respiratory failure and cardiogenic shock due to high output fistula. The fistula was treated endovascularly, the patient's condition was stabilized, and he was safely taken for redo open repair 6 days later.

\section{Endovascular Reinterventions}

One patient was treated with TEVAR extension for distal type 1 endoleak and it resolved. Another patient underwent coil embolization of the pseudoaneurysm for endoleak. There were 4 other type 1 endoleaks. One was the planned conversion described above, 1 without aneurysm resolved slowly over a 2-year period, 1 refused further treatment, and the last patient is being monitored expectantly.

\section{Engineering Analysis}

Seven patients $(32 \%)$ had an ideal result after the initial procedure. In 9 others, secondary success was achieved 
with an adjunctive procedure either at the time of the initial repair or at a later reintervention, for a rate of secondary success achieved in $73 \%$. Of the 6 incomplete repairs, 3 died in hospital and 3 others have untreated endoleaks. One died before the endoleak was addressed, 1 refused additional therapy, and the third is being monitored. Of the various modes of failure identified, 6 were deemed patient-related, 7 were deemed device-related, and 9 were delivery-related. In 7 patients mode of failure was attributable to 2 categories.

\section{DISCUSSION \\ Principal Findings}

For patients at excessive risk for conventional repair of acute ascending dissection, pseudoaneurysm, or chronic dissection, endovascular repair may offer a reasonable option over medical therapy. The morbidity is significant, but the procedure can be lifesaving in selected patients. Better outcomes may be achieved with an improved understanding of patient selection, and development of ascending aorta-specific devices and delivery systems for treating high-risk patients.

\section{Patient Selection}

Several different devices are now commercially available for stent grafting the descending aorta, and some of these are now approved for use in dissections as well as aneurysms. The ascending aorta is very different from the descending aorta in size, shape, hemodynamic forces, and proximity to other anatomic structures. These differences are important to consider when selecting endovascular therapy.

The proximity of the aortic valve and coronary arteries to the ascending aorta make it particularly challenging to obtain seal and fixation within the proximal landing zone. ${ }^{12-14}$ Current guidelines for stent grafting of the descending aorta typically recommend a $2-\mathrm{cm}$ length for the proximal landing zone, but this length is most important for treating degenerative fusiform aneurysm where there is greater potential for device migration compared with patients with the pathologies described in our experience. Others have suggested strict criteria for stent grafting the ascending aorta with a landing zone of at least $2 \mathrm{~cm}$ and aortic diameter $<40 \mathrm{~mm} .^{6,7,9,12}$ In our experience, this was most easily achievable in the subset of patients who presented with pseudoaneurysm and chronic dissection. In these patients, the mean distance from the highest coronary artery to the neck of the pseudoaneurysm or distal suture line was $3.8 \pm 1 \mathrm{~cm}$ and $5.1 \pm 1 \mathrm{~cm}$, respectively (Table 1 ). Preventza and colleagues ${ }^{7}$ recently described their successful experience with ascending stent grafting in 6 patients with pseudoaneurysm, none of whom had acute Type A dissection.

Several other reports of ascending stent grafting have been described in patients with Type A dissection. ${ }^{4-6,9,10}$
In our subset of patients with acute Type A dissection, 7 had the dissection extend at least partially into the aortic root and 4 patients had at least moderately severe (ie, $3+$ ) aortic insufficiency. The mean distance from highest coronary to entry tear measured only $1.8 \pm 0.3 \mathrm{~cm}$ on center line of flow analysis, and the aorta was short. In both patients with intramural hematoma, it extended to the root. Despite these anatomic challenges, the valve function improved to mild in each of those 4 patients, and the patients with intramural hematoma fared very well. Nonetheless, all 3 early deaths occurred in patients presenting with acute Type A dissection. The 3 late deaths also occurred in this subset, but only one of those was potentially related to the dissection and operation. All 6 patient-related modes of failure occurred in these patients as well, and they represent the sickest cohort of the series. Although the entry tear was particularly close to the aortic root in several of these patients, the greater challenge occurred in those patients who had that finding in combination with a preexisting ascending aneurysm that presented as acute dissection. This combination was particularly bad because it led to difficulty with both the proximal and distal landing zones.

Understanding the limitations of this technology is critical to understanding its application. Even in a patient in whom an ideal definitive repair may not be expected with endovascular therapy, the treatment may still be valuable. In 2 of our patients we were able to bridge them from presentation in extremis to an eventual open repair that they may not have tolerated otherwise.

\section{Device Considerations}

Currently available stent grafts do not fully address the unique features of ascending aortic anatomy. The ascending aorta is typically broader in diameter than the descending aorta, and because it is a curved structure, there is a significant difference in lengths along the greater and lesser curves. In a few instances the ascending aorta was long enough to use a $10-\mathrm{cm}$ thoracic stent graft, but in most, adequate coverage was obtained by the use of aortic extension cuffs from either thoracic or infrarenal stent-graft systems. Multiple cuffs were used in most patients. The length along the greater curve was accurate in predicting the adequate length needed. Ascending aorta-specific device designs should include larger-diameter devices with a precurved shape in shorter lengths (on average about 7-9 cm). ${ }^{12-14}$ Improved conformability of the device to fit the curvature of the aorta and provide a better seal along entry tears could also be important characteristics to consider.

Excessive hemodynamic forces in the ascending aorta typically lead to variations in diameter of the normal ascending aorta by at least $8 \% .^{13}$ These changes may compromise precise deployment of the devices and can also increase the risk for late migration. In our patient 
with the late incidental finding of device migration, we suspect the device was undersized. For chronic disease indications we recommend oversizing by about $20 \%$ instead of the typical $<10 \%$ recommended for acute dissections.

Other future considerations for durable device design include the use of active fixation adjuncts, such as barbs, or off-the-shelf versions with a branch for the brachiocephalic artery. ${ }^{15}$

\section{Delivery for Ascending TEVAR}

The most common inadequacies were related to delivery issues. The device not only commonly needs to be accurately positioned with a margin of error of $<1$ to $2 \mathrm{~mm}$, but it needs to lie coaxially across the sinutubular junction. All 3 of the patients who had inadvertent coronary coverage had the device delivered from a transfemoral approach and 2 of these even had the at-risk coronary artery accessed preemptively with a coronary artery wire that did not prove to be very helpful. Use of the ventricular apex or axillary artery shortens the length of delivery and therefore may improve accuracy. In patients who had transapical delivery, the wire access was established "through and through" from the apex to the left axillary, providing more ability to adjust the position of the device at the time of deployment. Fortunately, in 2 patients in whom the coronary artery was covered, we were able to salvage the procedure by repositioning the device with inflation of and ejection against a large conformable balloon. Improved delivery systems should allow for a graduated deployment to improve accuracy and the potential for repositioning.

Hussain and colleagues ${ }^{16}$ reported their experience using atrial septal defect closure devices for treating ascending aortic pseudoaneurysm in 6 patients with moderate success. We found this approach useful as a bailout in a patient in whom we could not traverse a mechanical valve. This highlights the importance of having a delivery system with a short tip, and more importantly the flexibility to provide both endovascular and open rescue procedures to address potential complications in these evolving procedures performed on high-risk patients. ${ }^{17}$

\section{CONCLUSIONS}

Endovascular therapy of the ascending aorta is feasible and can be lifesaving in patients who are too high risk for open repair. Better outcomes may be achieved with development and refinement of new stent graft devices and delivery systems specifically designed to treat ascending aortic pathology.

\section{References}

1. Centofanti P, Flocco R, Ceresa F, Attisani M, LaTorre M, Weltert L, et al. Is surgery always mandatory for type A aortic dissection? Ann Thorac Surg. 2006;82:1658-64.
2. Hagan PG, Nienaber CA, Isselbacher EM, Bruckman D, Karavite DJ, Russman PL, et al. The International Registry of Acute Aortic Dissection (IRAD): new insights into an old disease. JAMA. 2000;283:897-903.

3. Trimarchi S, Nienaber CA, Rampoldi V, Myrmel T, Suzuki T, Mehta RH, et al. Contemporary results of surgery in acute type A aortic dissection: The International Registry of Acute Aortic Dissection experience. J Thorac Cardiovasc Surg. 2005;129:112-22.

4. Roselli EE, Brozzi N, Albacker T, Lytle BW. Transapical endovascular ascending repair for inoperable acute type a dissection. JACC Cardiovasc Interv. 2013;6:425-6.

5. Thnken K, Sze D, Dake MD, Fleischmann D, Van der Starre P, Robbins R Successful treatment of Stanford type A dissection by placement of a covered stent graft in the ascending aorta. J Thorac Cardiovasc Surg. 2004; 214:1808-10.

6. Lu Q, Feng J, Zhou J, Zhao Z, Bao J, Feng R, et al. Endovascular repair of ascending aortic dissection. J Am Coll Cardiol. 2013;61:1917-24.

7. Preventza O, Henry MJ, Cheong BY, Coselli JS. Endovascular repair of the ascending aorta: when and how to implement the current technology. Ann Thorac Surg. 2014;97:1555-60.

8. Kolvenbach RR, Karmeli R, Pinter LS, Zho Y, Lin F, Wassiljew S, et al. Endovascular management of ascending aortic pathology. J Vasc Surg. 2011; 53:1431-8.

9. Ronchey S, Serrao E, Alberti V, Fazzini S, Trimarchi S, Tolenaar JL, et al. Endovascular stenting of the ascending aorta for type A aortic dissections in patients at high risk for open surgery. Eur J Vasc Endovasc Surg. 2013;45: 475-80.

10. Senay S, Alhan C, Toraman F, Karabulut H, Dagdelen S, Cagil H. Endovascular stent-graft treatment of type A dissection: case report and review of literature. Eur J Vasc Endovasc Surg. 2007;34:457-60.

11. Nordon IM, Hinchliffe RJ, Morgan R, Loftus IM, Jahangiri M, Thompson MM Eur J Vasc Endovasc Surg. 2012;44:406-10.

12. Moon MC, Greenberg RK, Morales JP, Martin Z, Lu Q, Dowdall JF, et al Computed tomography-based anatomic characterization of proximal aortic dissection with consideration for endovascular candidacy. J Vasc Surg. 2011 53:942-9.

13. Lu TC, Huber CH, Rizzo E, Dehmeshki J, von Segesser LK, Qanadli SD Ascending aorta measurements as assessed by ECG-gated multi-detector computed tomography: a pilot study to establish normative values for transcatheter therapies. Eur Radiol. 2009;19:664-9.

14. Sobocinski J, O’Brien N, Maurel B, Bartoli M, Goueffic Y, Sassard T, et al Endovascular approaches to acute aortic type A dissection: a CT-based feasibility study. Eur J Vasc Endovasc Surg. 2011;42:442-7.

15. Haulon S, Greenberg RK, Spear R, Eagleton M, Abraham C, Lioupis C, et al Global experience with an inner branched arch endograft. J Thorac Cardiovasc Surg. 2014 [Epub ahead of print].

16. Hussain J, Strumpf R, Wheatley G, Diethrich E. Percutaneous closure of aortic pseudoaneurysm by Amplatzer occluder device-case series of six patients Catheter Cardiovasc Interv. 2009;73:521-9.

17. Roselli EE, Idrees J, Mick S, Kapadia S, Tuzcu M, Svensson LG, et al. Emergency use of cardiopulmonary bypass in complicated transcatheter aortic valve replacement: importance of a heart team approach. J Thorac Cardiovasc Surg. January 15, 2014 [Epub ahead of print].

\section{Discussion}

Dr Roselli. Ascending aortic disease is something that we commonly see in our practice and it has represented a growing area of indications for cardiovascular surgery at the Cleveland Clinic. We perform more than 600 elective operations on ascending aortas per year and our mortality rate has been low. It is a very safe operation and durable, too. Even in emergency indications, although the mortality is higher, it has been consistently $<10 \%$. Nonetheless, some patients are deemed too high risk for conventional repair, and over an 8-year period we have treated 22 of these patients with endovascular approaches to the ascending aorta. Nine patients had acute Type A dissection and 2 had an intramural hematoma with penetrating ulcer in the 
ascending aorta. Nine had pseudoaneurysms and 2 had particularly complicated chronic dissections requiring intervention. As Bruce Lytle says, "No patient really is inoperable," but all of these patients had been deemed to be too high risk for an open operation. I only show some of the details here about age, the size of the aorta, the fact that most of them required a reoperation, that many were emergencies, and a handful of patients had severe aortic insufficiency, but it was believed that all of these patients had the potential for a meaningful recovery because they had a decent quality of life before the emergency event. The truth is that the details of what made each a so-called inoperable patient could make for a case report on each individual patient, but they are a high-risk group of patients.

Before we perform this procedure we do our best to understand the anatomy. In a retrospective fashion, we collected a lot of data on what these patients' aortas looked like. This was done using 3-dimensional software and by doing a detailed computed tomography imaging analysis, looking at-most importantlythe diameters at the proximal and distal landing zones that were often at the sinotubular junction, but in many patients this was within a previous graft. We also measured the length of the aorta and it is important to note that these measurements are not only made at a center-line-of-flow type of analysis but also by making measurements along the greater and lesser curves. Details were also gathered about the branch vessels and details of where the entry tear occurred in relation to the aortic root structures. All of these procedures were performed under general anesthesia in a hybrid operating room and various modes of access to get to the ascending aorta were used. Ten patients received a transfemoral delivery of devices, 5 had a transaxillary delivery of devices, and 7 had the devices delivered in a transapical fashion. We decreased cardiac output to maintain stability during deployment in all these patients. In 1 patient, we electively performed this using cardiopulmonary bypass because we did not think she would tolerate rapid ventricular pacing, and in the rest rapid ventricular pacing was used, much like what has been done with transcatheter valve replacement. In 5 patients we preemptively accessed a coronary artery or coronary bypass graft because of concerns that we might be close to that vessel, and all of these patients had an assessment of their aorta before and after the procedure using contrast-enhanced angiography and intraoperative transesophageal echocardiography. Here is an example of a few cases: First is a patient who had an acute Type A dissection that was treated in a transapical approach. We had a through-and-through wire going in and out the left axillary artery. The device was deployed using rapid ventricular pacing. This patient had quite severe aortic insufficiency and had a marvelous result with only a little bit of flow into that false lumen and improvement in aortic insufficiency.

Next is a patient who had a transaxillary delivery of the device for pseudoaneurysm. The abdominal extension cuff was delivered through a conduit sewn onto the left axillary artery with a wire going across the valve, and an angiography catheter from below. Once this device is positioned in place, the heart is rapidly paced and the device is deployed in a graduated fashion. That felt like a really long period of time of rapid ventricular pacing during the procedure.

A patient who had a chronic dissection and at a routine follow-up study was noted to have the arch grow rapidly from relatively normal size at the initial postdischarge computed tomography scan to $>6.5 \mathrm{~cm}$. Close analysis of the scan showed that the false lumen seemed to be filling from a small entry tear at the distal suture line. This patient also underwent a transfemoral ascending repair. The angiography filled the false lumen in this right anterior oblique projection and delivery of the device from below. We ballooned the device to get it to conform across the distal suture line where we thought that entry tear was. Again, that is done with rapid ventricular pacing to avoid displacement of the device. Stent grafts were placed in 21 out of 22 patients. They were a mix of mostly commercially available, but a couple of custom-made devices. Most of them were the Zenith device (Cook, Bloomington, Ind) and many patients required multiple devices. In 1 patient we could not cross a mechanical valve with a stent graft so we opted to use an atrial septal defect closure device to close a fistula between a pseudoaneurysm and the right main pulmonary artery. That patient later went for open repair.

Our early outcomes were acceptable in this high-risk group of patients. Only 3 of 22 had an operative or hospital or 30-day mortality. There were a few strokes and myocardial infarctions, and a couple of patients had a tracheostomy; no patients had dialysis-dependent renal failure. There were intraoperative adverse events. One patient died on the table. Although we were able to successfully seal off the hole in that patient's ascending aorta, that aorta had actually ruptured and eroded into his left atrium and he bled out from his left atrium. That patient was in his mid-80s and presented with a Type A dissection and a ruptured chronic aneurysm.

Two patients had open conversion at the time of the procedure, 1 because of a retained delivery system. We circ-arrested that patient and through an aortotomy removed the delivery system and left the stent graft in place. Another patient had coronary occlusion, was placed on cardiopulmonary bypass, and was converted to standard repair. Another patient was placed on cardiopulmonary bypass because she did not tolerate the rapid ventricular pacing very well, but after about a half hour on the pump she recovered and was easily weaned from the pump.

Two patients had inaccurate deployment of the device and we were able to salvage them endovascularly with balloon repositioning. Consider 1 of these patients: A woman aged 80 years had a penetrating ulcer and intramural hematoma. On the angiogram after we deployed the device the right coronary fill is seen, but no filling in the left coronary artery. The end of this device sat pretty low in the root. There was quite a bit of aortic insufficiency, as well. No surprise, there was a rapid drop in the ST segments and some serious hypotension with a blood pressure of $64 / 25 \mathrm{~mm} \mathrm{Hg}$. We had the lines on the table and we were about to connect the patient to cardiopulmonary bypass, but I wanted to try 1 more thing. The balloon went up in that graft and because of the heart ejecting against it the device moved away from the left main coronary artery. This still felt like rapid ventricular pacing, but the completion angiogram showed really great filling of the left main coronary artery, and within 2 minutes her STs completely recovered and her blood pressure was $118 / 45 \mathrm{~mm} \mathrm{Hg}$. She went home on postoperative day 5 .

There were 3 were late deaths; 1 patient died in a nursing home. He sustained a stroke after the procedure. Actual survival was 
reasonable for these very high-risk patients but 4 patients required later open conversions. Two were planned and 2 were unplanned. One unplanned surgery was in a patient who had a device migration late in follow-up and was in much better shape to tolerate an open operation. One patient developed an apical pseudoaneurysm from a wire injury that was easily repaired. The 2 patients who underwent planned conversions were in extremis when they came in. They were stabilized with the ascending endovascular operation and were later repaired with open surgery. Several endoleaks occurred. Two were treated endovascularly; 1 was treated open and 1 resolved on its own. One is being monitored, so we achieved technical success in 7 patients primarily, and in 9 patients secondarily for a rate of treatment success of $73 \%$, but there were multiple near misses and some comorbidities, as I have shown you already.

Some additional lessons were learned from this. We learned a bit about the disease process. In the patient with chronic dissection there was a wonderful result only 3 months after stent grafting the entry tear in that suture line.

A patient with a ruptured aneurysm was very early after a recent percutaneous coronary intervention that was needed for a complication from a recent open repair. We placed the stent graft. We got some thrombosis formation, but he had a persistent endoleak. I eventually took him back for open repair and the stent graft actually held. There was quite a mess in his chest and this patient lived to tell us that these therapies should be considered complimentary and not competitive to each other.

Stent graft migration occurred late in 1 patient and this was pretty scary, but the patient had no serious sequelae from it. He was able to later have that device removed. We probably undersized that device and that is something that we learned.

A patient who had a persistent endoleak but no aneurysm associated with it by 2 years had complete resolution and healing of her Type A dissection.

We did a focus analysis of the outcomes in these patients with an attempt to improve quality and understand how we can do these procedures better. We found inadequacies in 15 patients and there are 22 issues that were described as patient-related, device-related, or delivery-related in an attempt to improve our ability to provide this therapy. We need better devices. We need better stent grafts that are more conformable, that are precurved and potentially with branches. And we need more accurate delivery systems to improve this technique.

In conclusion, ascending endovascular therapy is feasible and is an effective life-saving therapy. Patient selection is important, but the application of it as a bridging therapy may allow for broader use of this technology. As we get better devices and delivery systems, I am certain that this technology will grow to improve care for patients. Thank you very much.

Dr Miller (Palo Alto, Calif). Thank you for returning to the Western. If you keep doing this, we will make you an honorary member. You conducted shoestring catches in unbelievable pathology and made heroic attempts; it is amazing it worked in as many as it did. Believe it or not, 1 of these crazy things was done at Stanford when both Scott Mitchell and I were out of town. Mike Dake and a resident did it on a patient who was aged 90 years, blind, and in a wheelchair, but she lived about 2 or 3 years with a big leak, so it does have a role. You are handicapped by the design of what is available, but before I get to that, I think for a small opening in a pseudoaneurysm, it is going to be pretty safe. For a landing zone in a graft, your heart rate does not go up too much, but for the acute dissection patient, it is a different story and you discussed using this technology as a bridge. Tell us where you see this helping us now given the current limitations and what devices are available. Which patients and how would you bridge and what are you going to bridge?

Dr Roselli. That is a question I would like to know the answer to, to be honest with you, Dr Miller, and thank you for the kind comments. Although there is plenty of data out there about our results with treating acute Type A dissections, it is all surgical data. Very little was written about the patients we choose not to operate on. In the International Registry of Acute Aortic Dissection series, up to $25 \%$ of patients do not get an operation and in our own experience in Cleveland-although this data is not published-it is somewhere between $10 \%$ and $15 \%$ of patients who show up with a Type A dissection. Many of those are patients who come in comatose and brain dead or maybe really old and demented. We do not touch those patients, but there are quite a few patients like the ones we have chosen here who had a pretty decent lifestyle before they came in with a very sick situation. A patient, for example, who is aged 80 years or older and maybe needs a redo operation or is struggling with heart failure from aortic insufficiency or from some other complication is 1 we selected. I have been really pleasantly surprised to see that we have been able to get them through the endovascular therapy, some with a definitive treatment. One patient, for example, who was aged about 50 years had untreated thyroid disease, came in with an ejection fraction of $10 \%$, and she was morbidly obese. She had complete healing of her dissection after stent grafting, got treated for her thyroid disease, and her ejection fraction normalized. I kept waiting for the aorta not to heal, but it has.

With regard to the bridging patients, 2 patients in particular who stand out are patients who had a rupture of the dissection. I think what I have learned from the postanalysis of this, even though it is a small group of patients, is that the patients with Type A dissection that occurs in the setting of a preexisting aneurysm are those who are particularly worrisome. They are often older and they often have some other complication associated with that dissection like an erosion into a neighboring structure. In those patients, we may be able to seal off the entry tear, but I am not sure we are going to get the whole aorta to heal.

Dr Miller. The design limitations use extension cuffs and thoracic stent grafts to $10 \mathrm{~cm}$. It is the shortest commercially available and I can see how that would bug you and make you plead for shorter, curved, tapered, and branched grasp. It is probably going to be a long time before any commercial firm sees the market big enough to justify that. We do not even have custom-design devices for dissection of acute dramatic tear. It is just not a big enough market for the companies to invest that kind of money so I do not think we are going to see the devices you are looking for become available. Do you have any hints for what we can do? Would you have rather gone with a short extension cuff instead of a $10 \mathrm{~cm}$ Conformable Gore TAG (CTAG) (W. L. Gore \& Associates, Flagstaff, Ariz)? 
Dr Roselli. In patients where I used the 10-cm CTAG-there were only a few-the aorta has been long enough. Another thing that I learned was the business about sizing; although for the descending aorta and even for the thoracoabdominal branches we always size on a center line of flow kind of analysis, but I think a measurement along the greater curve is actually probably most accurate for sizing in the ascending aorta. If that greater curve length is close to about $10 \mathrm{~cm}$, that is probably the best device because it is the most conformable. And, also, you can have it extend up toward the brachiocephalic artery and get away with a little bit of covering. The nice thing about abdominal extension cuffs, although the delivery system is short so you often have to deliver it through an axillary or an apical approach, is that it is a very controlled delivery. It is an important feature because that is where we have had trouble with coronary occlusion, with difficulty in accuracy.

Dr Miller. Were both coronary occlusions transfemoral or subclavian? Any transapical coronary occlusions?

Dr Roselli. There were no transapical coronary occlusions. They were all transfemoral.

Dr Miller. That is probably to be expected, right? Don't you think the transapical approach offers an advantage here?

Dr Roselli. I think that is very true. A shorter delivery system may improve accuracy.

Although the stent graft devices need to be shorter and need to be conformable and curved, and so on, it is probably just as important, if not more important, to have a better delivery system that allows us to be more accurate and get coaxial at the sinotubular junction.

Dr Miller. Absolutely. You would still go with a 10-cm CTAG or other commercially available thoracic device or whatever preferentially? Or would you prefer a shorter extension cuff because too much length is your biggest problem here?

Dr Roselli. I actually prefer the $10 \mathrm{~cm}$ if I think it is going to fit. The problem is, for most patients the ascending aorta is only about $8 \mathrm{~cm}$.

Dr Miller. Thank you very much. I am sure others have questions about this wild stuff.
Dr Roselli. It is a privilege.

Dr Jones. I just have 1 question. There were 3 patients who had $3+$ or greater aortic insufficiency. What happened after the procedure and how did those patients do?

Dr Roselli. Actually it was 4 patients. I am sorry if the slide was inaccurate. The aortic insufficiency got better in all of them, surprisingly, and 3 were in patients with a dissection and 1 had a large intramural hematoma that extended down toward the root. Thinking about the mechanism of aortic insufficiency in those patients, none of it was structural at the cusp level. All of it was because of commissural displacement and by getting that commissural post resuspended. Immediately we saw improvement in aortic insufficiency in all 4 of those patients. So it went from this moderately severe $3+$ or more level of aortic insufficiency to only about 1 to $2+$ and it stayed that way as their aortas healed, and in all those patients the aorta seemed to heal down low at the proximal end of the ascending aorta. Two patients had persistent endoleak but it was distally up near the brachiocephalic artery and did not seem to cause them trouble with their aortic valve, which was a surprisingly good finding because it gives a little bit of reassurance that we can offer this to other patients in the future and that will not be a necessary contraindication.

Dr Shemin (Los Angeles, Calif). In patients with aortic insufficiency, why not use the adjuvant cardiopulmonary bypass - a brief run-instead of looking at the rapid atrial pacing where aortic insufficiency can get worse and you can potentially have a cardiac arrest and further complicate the situation?

Dr Roselli. Good question and we learned that. In the 1 patient who was converted to cardiopulmonary bypass who had a little trouble after the rapid ventricular pacing, it was because she had aortic insufficiency. In a subsequent patient we electively used cardiopulmonary bypass but the rapid ventricular pacing is still pretty well tolerated in many of these folks. It depends what their left ventricular function is like and we always have the pump wet, ready, lines on the table, and a plan for going on pump, including sewing a graft to the axillary artery, in these patients. 